\title{
POINT CLOUD DATASET AND FEM FOR A COMPLEX GEOMETRY: THE SAN LUZI BELL TOWER CASE STUDY
}

\author{
I. Selvaggi ${ }^{1 *}$, G. Bitelli ${ }^{1}$, E. Serantoni ${ }^{2}$, A. Wieser ${ }^{2}$ \\ ${ }^{1}$ Department of Civil, Chemical, Environmental and Materials Engineering (DICAM), University of Bologna, \\ Viale del Risorgimento 2, 40136 Bologna, Italy - (ilenia.selvaggi, gabriele.bitelli)@unibo.it \\ ${ }^{2}$ ETH Zurich-Institute of Geodesy and Photogrammetry, Stefano-Franscini-Platz 5, Zurich 8093, Switzerland \\ (eugenio.serantoni, andreas.wieser)@geod.baug.ethz.ch
}

KEY WORDS: Cultural Heritage, Terrestrial Laser Scanning, three-dimensional modeling, Finite Element Model

\begin{abstract}
:
Detailed three-dimensional reconstruction of heritage objects is crucial for different purposes, such as analysis, preservation and maintenance, among others. Geomatics techniques allow acquiring complex and comprehensive information about geometry and current conditions of the surveyed objects in a short time, which is a great advantage for documentation and historical archives. The reconstruction of three-dimensional models is often performed using either image-based techniques, mainly Close Range Photogrammetry (CRP), including Structure from Motion approaches (SfM), or range-based techniques, such as Terrestrial Laser Scanning (TLS). These approaches have been widely applied in the field of Cultural Heritage to support multidisciplinary studies, from simple documentation to the monitoring of historical buildings, in restoration works or for structural analysis checks.

The present paper aims at exploring the potential contribution of Geomatics to Structural Engineering, by investigating capabilities and advantages of TLS for a vertical structure. The experiments presented herein were carried out in a notable case study, the San Luzi church, located in Zuoz (Switzerland) in the Upper Engadin. Its bell tower is about $60 \mathrm{~m}$ high and is equipped with four bells. Strong vibrations caused by the ringing of the bells have been observed in the past, and a structural model was desired to enable numerical evaluations of the response of the tower to various load situations by FEM.
\end{abstract}

\section{INTRODUCTION}

Geomatics techniques are widely used for data gathering in different fields of civil engineering. The reconstruction of threedimensional models is often performed using integrated techniques in data acquisition. The most commons include image-based methods like Structure from Motion approaches (SfM) and range-based techniques, such as Terrestrial Laser Scanning (TLS). The versatility of these techniques allow their use in several areas (Guarnieri et al., 2017; Mill et al., 2013; Sánchez-Aparicio et al., 2014)

Concerning terrestrial laser scanning technology, this wellknown technique enables to quickly getting three-dimensional spatial information. In particular, it allows to obtain a very detailed and complete description of the object (Vosselman and Maas, 2010). Of course, the analysis process directly depends on the accuracy of the measured data (Boehler et al., 2003; Bolognesi et al., 2014).

With its high level of detail, TLS is very versatile and could be used, for example, in the assessment of building conditions (Tang and Akinci, 2012), computing accurate parametric models of complex objects (Bauer and Polthier, 2009), or taking advantage for the preservation of a building damaged from an earthquake (Bitelli et al., 2016; Brumana et al., 2018).

With increasingly complex architectures, one of the key problems in civil engineering is the improvement of the reliability of the constructed structures. Masonry walls compose the majority of these buildings. For this kind of material, the Finite Element (FE) approach has been proven as a valid solution as close as possible to the real geometry. As known, the FE models are characterized by a finite number of elements.
A typical challenge at the interface between Geomatics and Structural Engineering is the conflict between the potentially huge amount of data characterizing the geometry of the objects (e.g. the point cloud dataset) and the specific, often simplified, data required for the FE models.

Several studies addressed the derivation of the FE model from Geomatics data. Castellazzi et al. (2015), through a semiautomatic procedure in which a slicing of the polygonal model derived from the point cloud dataset was performed, obtained a 3D model suitable for structural analysis software. The research of Barazzetti et al. (2015) carried out the generation of the model by exploiting a preliminary accurate Building Information Modeling (BIM), through an algorithm able to convert the point cloud dataset into a BIM model and then into a FEM. All the works have a common point: the goal to obtain a reduction of the amount of raw data without losing important details in order to not compromise the final analysis (Selvaggi et al., 2018). Buildings belonging to the Cultural Heritage are often composed by masonry, and their structural behaviour is strongly related to the geometric characteristics of the walls. Point clouds can play a fundamental role in structural simulation of existing constructions, especially in the case of complex historical structures for which sufficiently accurate and complete maps may not be available.

The present paper aims at demonstrating how it is possible to obtain a complete FE model, without reducing the initial dataset, considering a high-rise historical building. As case of study, the San Luzi bell tower, in Switzerland, will be analysed.

Corresponding author 


\section{CASE STUDY}

The San Luzi church is located in Zuoz (Switzerland) in the Upper Engadin. The study focuses on its bell tower (Figure 1). The total tower height is about $60 \mathrm{~m}$, and its cross section has a dimension of $5 \times 5 \mathrm{~m}$.

The tower is characterized by eleven floor plans (Figure 1, right). The tower is equipped with four bells of different weights. The San Luzi tower bell has the common Alps roof shape.

All the floors are carried by timber beams (Figure 2), except the two floors marked as $\mathrm{G}$ and $\mathrm{H}$ in Figure 3, which consist of reinforced concrete. All the stairs are in wood, as well as the beams, which carry the weight of the four bells.

The historical bell tower of the San Luzi church showed high vibrations during the ringing of the bells. In order to analyse the structural behaviour of the tower, a finite element model (FEM) of the bell tower was needed. Therefore, the goal of this study was to generate a precise FEM model, starting from the point cloud dataset obtained by Terrestrial Laser Scanning.
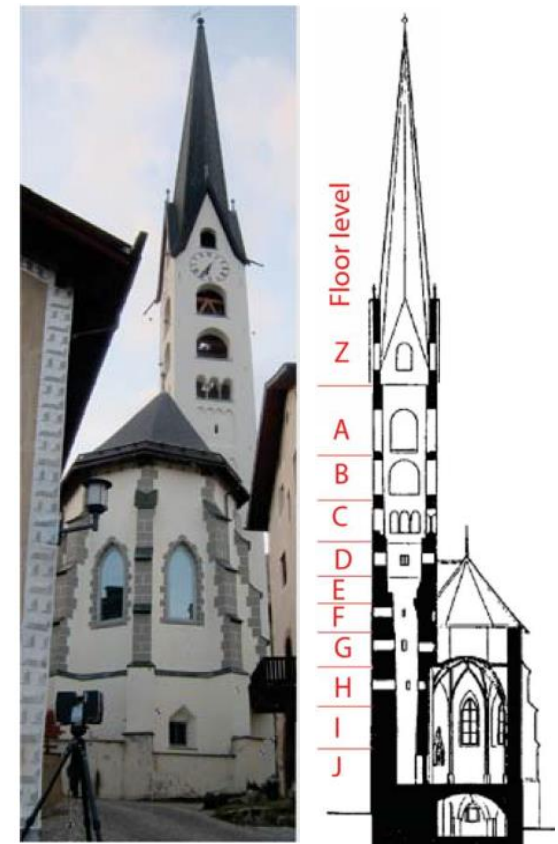

Figure 1. Left: San Luzi church bell tower. Right: cross section of the bell tower with its floor plan

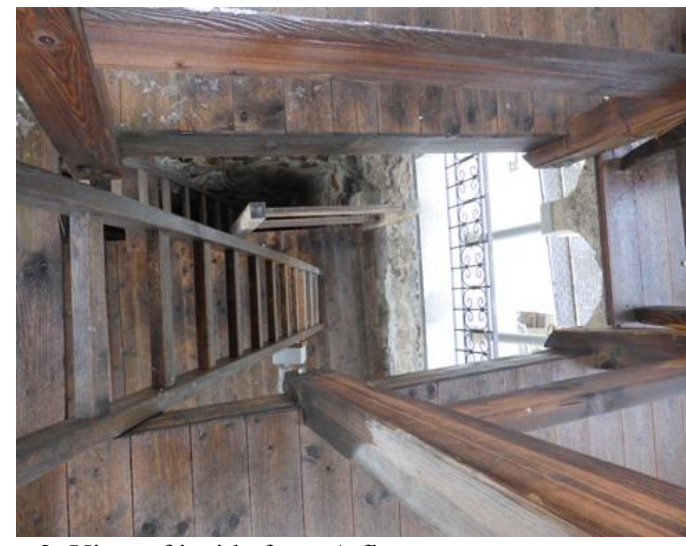

Figure 2. View of inside from A floor

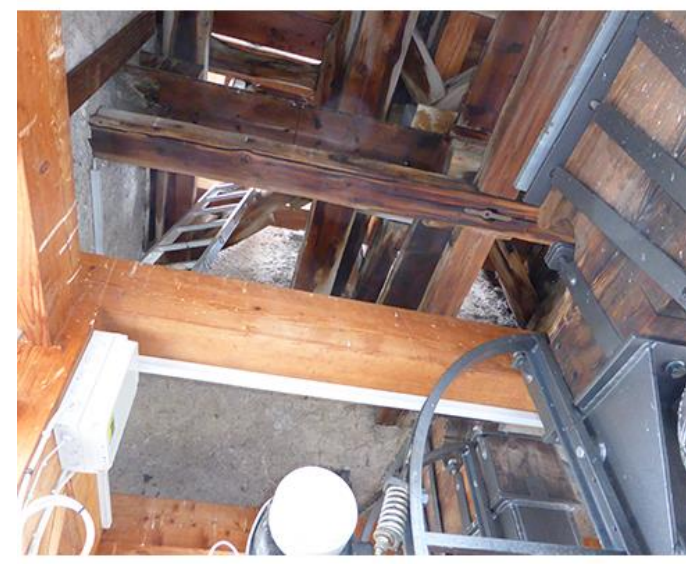

Figure 3. View of inside from B floor

\section{DATA ACQUISITION AND MODELING}

\subsection{Acquisition}

An initial inspection allowed determining all the possible locations for the instruments and the targets, considering the bell tower, the church and the village around the tower. The church and the bell tower were acquired using two total stations and a laser scanner (Figure 4). Checkerboard targets were placed inside and outside of the bell tower, the church and the crypt, to assure that registration of the individual scans would be possible with sufficiently high accuracy even with comparably little overlap provided that at least three targets were visible in each scan.

Test scans showed that the roof of the bell tower could not be covered by laser scans taken from the ground, likely because of the unfavourable angle of incidence and the resulting low power of the reflected signals. Some pointwise measurements of the roof were instead possible using a Leica MS50 in reflectorless mode. The Leica TPS1201+ was used for the measurements inside the bell tower.

The topographic network and all checkerboard targets have been surveyed by the Leica Nova MS50 total station thus allowing to not only register but even to georeference the scans. The total station measurements were carried out in two networks, one outside and one inside the bell tower with 18 points in common.

\begin{tabular}{|l|l|} 
Leica Nova MS50 \\
Range/Prism: $1.5-10000 \mathrm{~m}$ \\
Range/Surface: $1.5-2000 \mathrm{~m}$ \\
Ranging error to prism: $1 \mathrm{~mm}+1.5 \mathrm{ppm}$ \\
Ranging error to surface: $2 \mathrm{~mm}+2 \mathrm{ppm}$ \\
Angular Accuracy: 1 " (Hz\&V)
\end{tabular}

Figure 4. Surveying instruments with technical specifications 
The "Dorf" network (Figure 5) concerned all the points outside the tower, and the adjustment has been done by a free network solution, through the partial minimum-variance base of three chosen cadastral points. In this way, the geometric measurements later used to represent the tower within the FE model were not distorted by potential deviations of the coordinates of the cadastral points. Using the common points the adjustment of the internal "Turm" network was hierarchically connected to the "Dorf" network through constraints.

The measurements inside the tower exhibited high elevation angles and were potentially affected by centering errors. They were thus characterized by a greater level of uncertainty. Furthermore, there was a lack of visibility between the floors caused by beams and stairs. For these reasons, the common points allowed stabilizing the internal network and avoiding distortions of the model of the tower actually due to uncompensated deviations from the geodetic network measurements.

The bell tower, the church and the crypt have been scanned with the FARO Focus 3D S120. The laser scanner positions are shown in Figure 6. The same scanner was used both inside and outside the building.

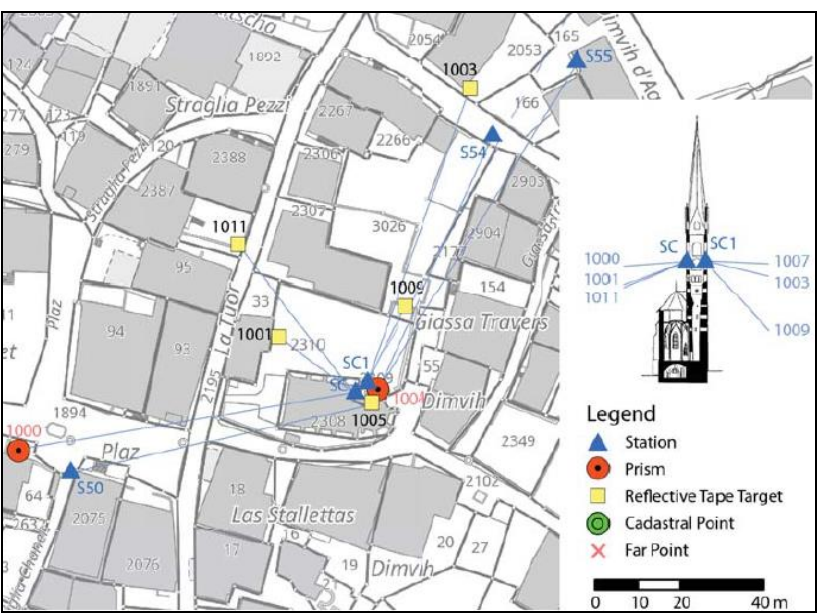

Figure 5. Network "Dorf", measurements inside the bell tower of the C-floor on the map and on the side view of the tower

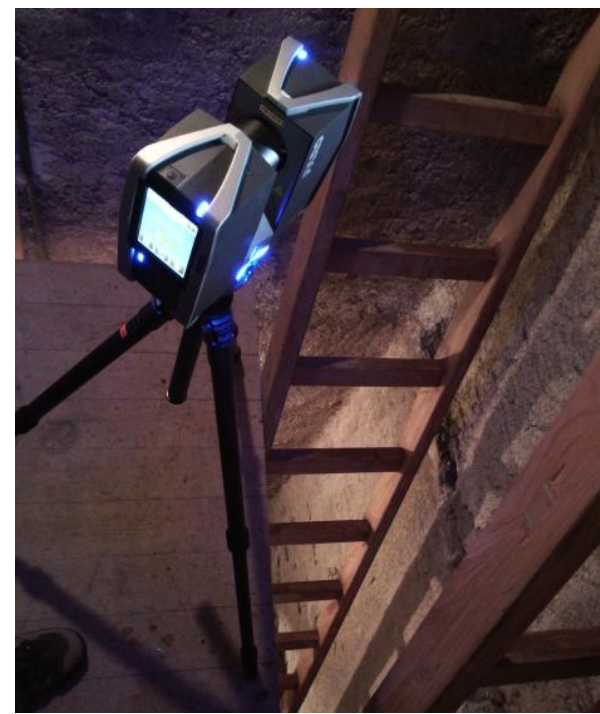

Figure 6. Position of the FARO Focus during a scan inside the tower

\subsection{Registration}

The total station raw data were processed using the software package rmGEO. At the final stage, the coordinates of the checkerboard targets have been determined by polar measurements.

Concerning the uncertainties of the observations of the free network adjustment of the Dorf network, the planimetric and the altimetric centering errors have a value of $0.5 \mathrm{~mm}$. For the Turm network, a value of $0.6 \mathrm{~mm}$ has been used.

The coordinates of the checkerboard targets were derived by polar measurements connected to the adjusted network and have standard deviations of less than two millimetres per coordinate within this network (local accuracy). The global accuracy within the Swiss cadastral system is not critical for the present purpose. It is a few centimetres, dominated by the uncertainties of the corresponding cadastral fixed points.

The registration and the georeferencing of the scans, as well as the first cleaning of the point clouds, were done in the software package FARO SCENE. In particular, the centres of the checkerboard targets have been automatically identified in all scans. The 46 scans have then been registered and georeferenced using the coordinates of the targets resulting from the total station measurements. Objects that were not of interest, such as railings or people, have been removed manually from the point clouds (cleaning).

After registration, georeferencing, and cleaning, the complete point cloud comprised about 25 million points. Of these, more than 9 million represented the bell tower and have been used as the starting point for the FE model generation.

\subsection{Polygonal model}

As known, laser scanning point clouds typically have strongly varying point density depending on the distances between the sensor and the scanned surfaces. This would negatively affect the derivation of an FE model. The point cloud was thus thinned out to a nearly uniform point density with an average point spacing of $0.15 \mathrm{~m}$ using the Geomagic software, and a voxel model with a constant and uniform spatial resolution was obtained using the approach proposed by Serantoni et al. (2017).

Some parts of the building could not be modeled because of missing data. For example, the roof of the tower was characterized by very sparse data and was thus omitted for the subsequent FE modelling. The area calculations was considered and the loads resultants were applied.

In this way, a point cloud dataset composed of slightly more than 3 million points has been obtained (Selvaggi, 2017) and was used to automatically generate a triangulated irregular network (TIN) using in-built functionality of Geomagic. This initial polygonal model consisted of almost 2 million triangles. However, there were many holes in the building, especially inside (due to the narrow spaces).

Furthermore, the polygonal model was very noisy. In Figure 7, the blue parts represent the continuous surfaces; the yellow ones are the cut or not-continuous surfaces; the green areas are the holes. The figure shows that the areas affected by holes are distributed all over the model. Correcting the TIN in order to obtain a continuous model for the further steps required labour intensive manual interaction, namely individual identification of all holes to be closed Figure 8 shows the resulting complete model. The missing roof was replaced by a horizontal plane closing the upper surface. The result of these steps was a continuous surface representing the external shell and the internal shell of the entire structure. 


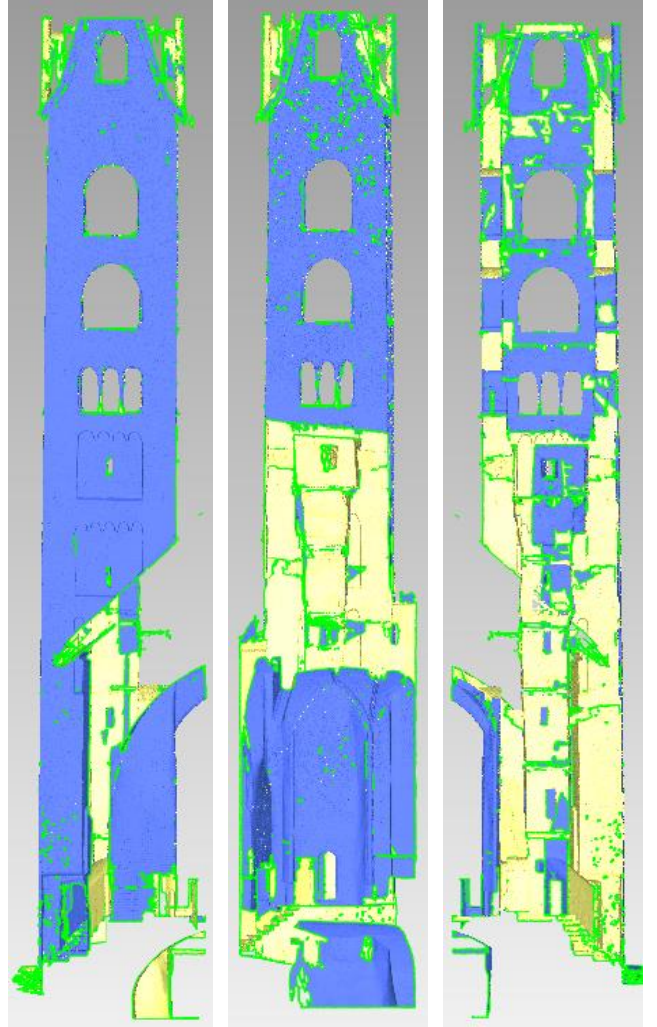

Figure 7. From left: Western, Southwestern and Southern fronts of the polygonal initial model. The green areas refer to non continuous surfaces (missing parts, cut elements etc...)

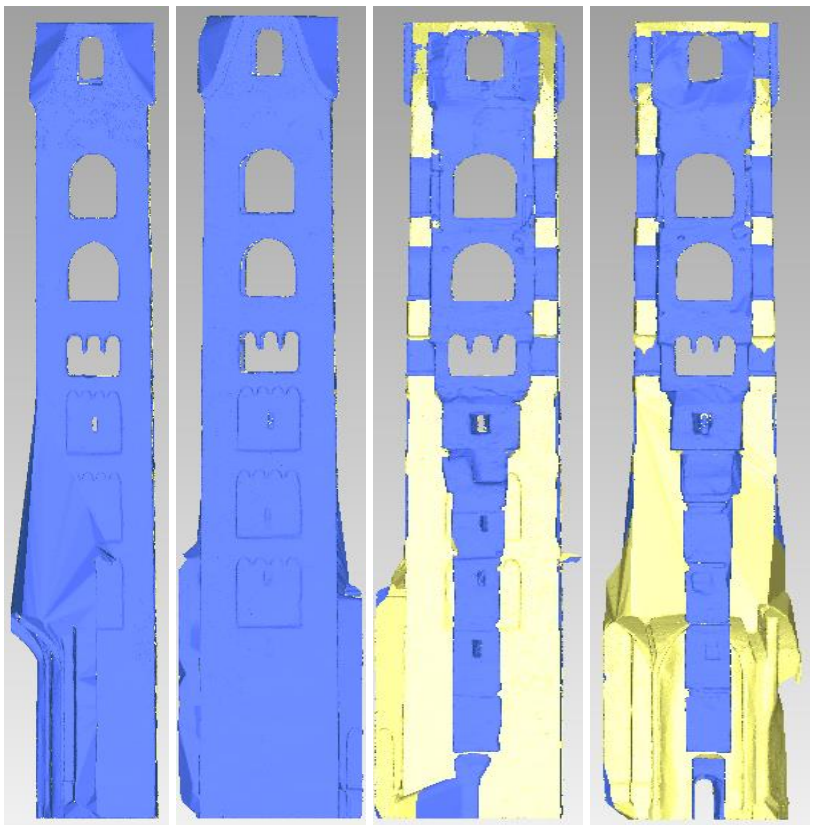

Figure 8. Corrected polygonal model of the external part. From left: West front, Northeast front, section of Southeast front and section of South front.

\section{TRANSFORMATION INTO AN FE MODEL}

\subsection{Geometric model}

The next step consisted in the conversion back from TIN model into a point cloud. However, as opposed to the initial point cloud data, this one was now homogeneous in terms of point density and represented the external and internal surfaces without holes. Then, in this application case, the TIN helped to manually correct, decimate and homogenize the point cloud of the structure. As previous said, this automatic process, starting from the polygonal model, allows to obtain a very homogeneous point cloud, correcting and improving, therefore, the original non-homogeneous, discontinuous and noisy dataset. The final point cloud was homogeneous and suitable for automatic script, without data loss. The final dataset contained two principal profiles: the first made by the points that belong to the external part and the second made by the points that belong to the internal part.

The alpha shape algorithm (Edelsbrunner and Mücke, 1994) has been applied to finally identify the finite elements representing the structure between the outer and the inner surfaces. An alpha shape can be intuitively defined as a generalization of the convex hull of a point dataset and is a continuous surface representation. The Eight-node linear brick elements (C3D8) arranged as voxels in coordinate space were introduced as candidates for the finite elements. The elements whose centre lies within the alpha shape were actually selected as part of the FE model (Figure 9). The result is a three-dimensional model with about 30.000 elements of size $25 \times 25 \times 25 \mathrm{~cm}^{3}$ representing the structure geometrically within the FE software.

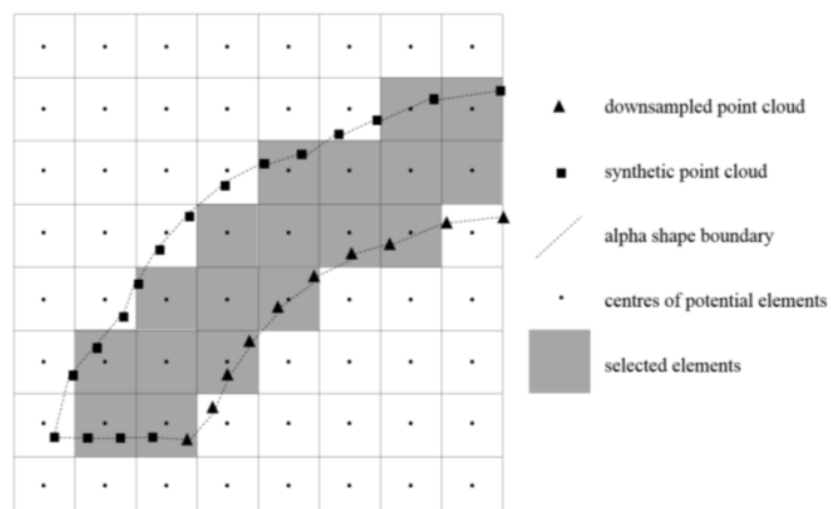

Figure 9. 2D sketch illustrating the generation of a voxel model out of the original point cloud (Serantoni et al., 2017)

By observing Figure 10, the green parts are the whole voxels, instead the orange parts are the sectioned voxels. It is possible to see how all the spaces between the internal and external surfaces have been filled with voxels. The windows are well shaped. 

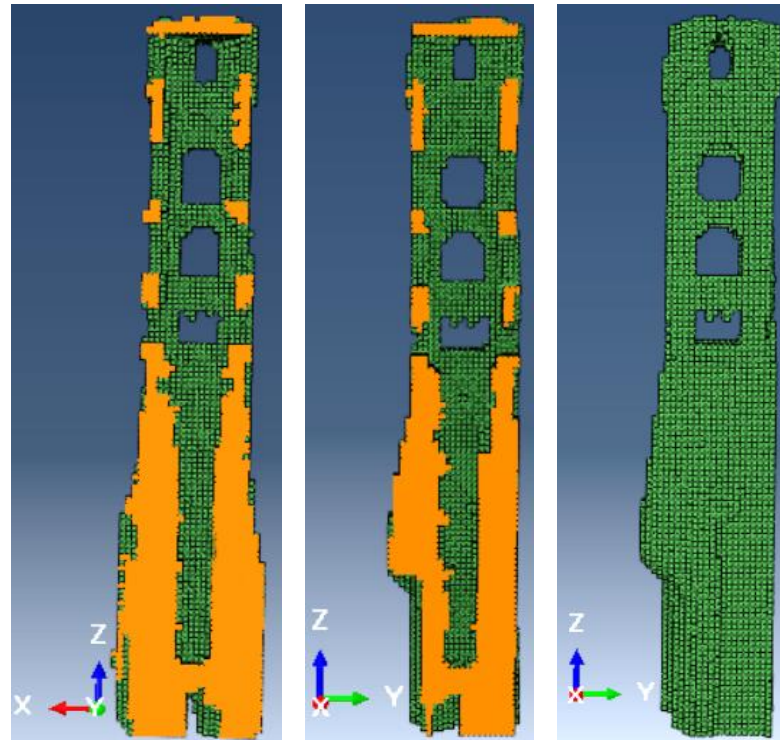

Figure 10. From left, cross section along $\mathrm{X}$ and $\mathrm{Y}$, and final voxel model. All the internal parts are correctly defined.

\subsection{Structural analysis tests}

The structural analysis has been done only in order to verify if the final voxel model was correct. Although there is not a survey or some indication about the materials composing the tower, characteristics parameters have been considered has input on the bases of similar cases available in literature (Castellazzi et al., 2015)

The only data available are the weights of the four bells, as reported in Figure 11.

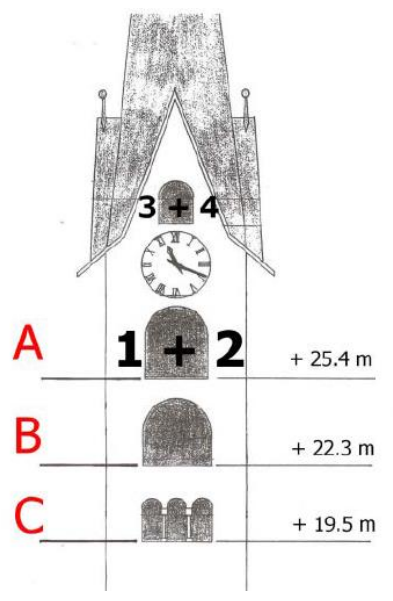

\begin{tabular}{|c|c|}
\hline Bell & Weight (N) \\
\hline 1 & 17000 \\
\hline 2 & 6480 \\
\hline 3 & 4000 \\
\hline 4 & 2600 \\
\hline
\end{tabular}

Figure 11. Position and weights (in Newton) of the bells (Cantieni et al., 2013)

Concerning the floors, a hypothetical section and an own weight have been taken into account for each beam and then these values have been multiplied for the effective clear span of the floor. The resulting values for each floor have been applied as concentrated forces on the masonry. Furthermore, the weights of the bells have been applied as concentrated forces on the masonry.

For the weight of the roof, a resultant of own weight and permanent loads has been calculated and applied.
The FE evaluation has been performed using the commercial software Abaqus. Constraints were considered in the ground, and translation along the direction of the church next to the tower has been constrained to zero.

In the Figures 12, 13, 14 the results of the numerical evaluations are presented for static and dynamic cases including the derivation of natural frequencies. The results of the dynamic analysis in terms of natural frequencies are also reported in Table 1.

\begin{tabular}{|c|c|c|c|}
\hline Mode n. & Mode description & $\begin{array}{c}\text { Max } \\
\text { Displacement } \\
(\mathrm{cm})\end{array}$ & $\begin{array}{c}\text { Frequency } \\
(\mathrm{Hz})\end{array}$ \\
\hline 1 & $\begin{array}{c}\text { 1st bending } \\
\text { mode (along X) }\end{array}$ & 1.006 & 1.5797 \\
\hline 2 & $\begin{array}{c}1 \text { st bending } \\
\text { mode (along Y) }\end{array}$ & 1.003 & 1.3621 \\
\hline 3 & Axial mode & 1.023 & 5.5365 \\
\hline 4 & Torsional mode & 1.315 & 4.4618 \\
\hline
\end{tabular}

Table 1. Natural frequencies analysis of the main mode shapes of the bell tower

Of course, this analysis must be regarded as a preliminary test and the obtained results represent only a first approximation, because the dimensions of the beams are all only assumed, and consequently the loads could be different (this depends on the chosen sections). Furthermore, the materials actually composing the tower and thus the corresponding material parameters were not available and also had to be assumed.

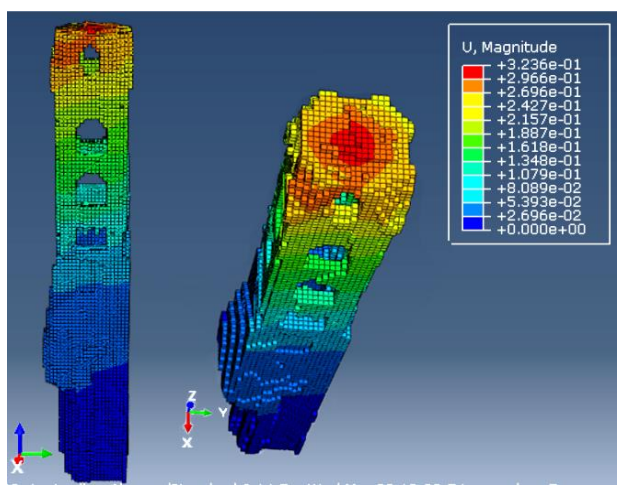

Figure 12. Static analysis

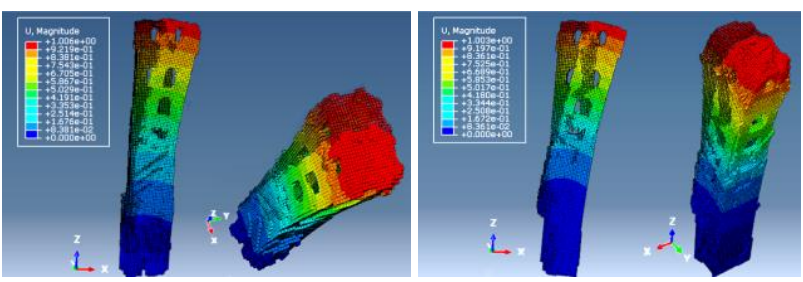

Figure 13. 1st bending mode along X (left) and along Y (right)
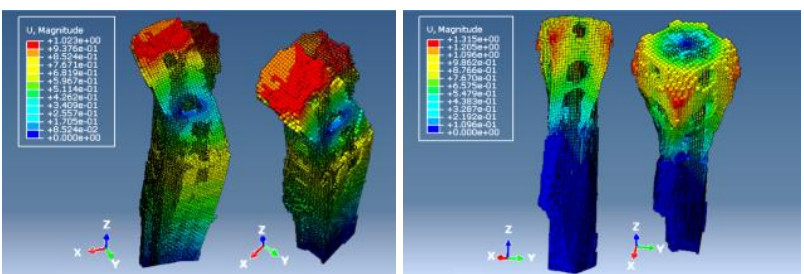

Figure 14. Axial mode (left) and torsional mode (right) 


\section{CONCLUSIONS AND OUTLOOK}

We have presented an approach to deriving a finite element model of a historic building by a semi-automatic process based on laser scanning point clouds. Point cloud processing and an alpha-shape approach to extract a closed hull of the building, comprising interior and exterior surfaces, have allowed deriving the geometry of the FE model. Material parameters and loads have been assigned manually, mostly based on assumptions.

We have demonstrated the approach using a bell tower, which allowed for a very particular case study. First, not all surfaces could be acquired both inside and outside. For example, the roof of the church and of the bell tower could be scanned only from outside and not from inside as well. Secondly, the software does not automatically distinguish the interior to the exterior of the building. For these reasons, manual cleaning of an intermediate model was necessary.

Nevertheless, the proposed procedure yields a detailed and sufficiently complete model, suited as an input for the structural analysis. The results of the static analysis and the natural frequencies resulting from the dynamic analysis indicated a correct definition of the voxel model. The data processing was demonstrated for one specific bell tower herein, but actually the procedure is generic and it can be applied to other structures and elements as well.

The availability of a reliable 3D model may be finally of interest for all the different disciplines involved (surveying, preservation and restoration, materials studies, structural analysis, etc.) through the establishment of a comprehensive Historical Building Information Model (HBIM).

\section{ACKNOWLEDGEMENTS}

The authors thank Dr. Reto Cantieni for the information provided about the bell tower, and Gudench Mischol for the access to the buildings. The laser scanning and total station data used herein were collected by the ETH students Patrick Hadorn and Martin Baumann under the supervision of two co-authors of this paper, of Stefan Conzett and Ekaterina Nozhova. They also carried out the network adjustment.

This work has been partially supported by the GAMHer project: Geomatics Data Acquisition and Management for Landscape and Built Heritage in a European Perspective, PRIN: Progetti di Ricerca di Rilevante Interesse Nazionale - Bando 2015, Prot. 2015HJLS7E.

\section{REFERENCES}

Barazzetti, L., Banfi, F., Brumana, R., Gusmeroli, G., Previtali, M., Schiantarelli, G., 2015. Cloud-to-BIM-to-FEM: Structural simulation with accurate historic BIM from laser scans. Simul. Model. Pract. Theory. doi:10.1016/j.simpat.2015.06.004.

Bauer, U., Polthier, K., 2009. Generating parametric models of tubes from laser scans. CAD Comput. Aided Des. doi: 10.1016/j.cad.2009.01.002.

Bitelli, G., Castellazzi, G., D’Altri, A.M., De Miranda, S., Lambertini, A., Selvaggi, I., 2016. Automated voxel model from point clouds for structural analysis of cultural heritage, Int. Arch. Photogramm. Remote Sens. Spatial Inf. Sci., XLI-B5, 191-197. doi:10.5194/isprs-archives-XLI-B5-191-2016, 2016.

Boehler, W., Bordas Vicent, M., Marbs, A., 2003. Investigating laser scanner accuracy. Int. Arch. Photogramm. Remote Sens. Spatial Inf. Sci., XXXIV-5, 696-701.
Bolognesi, M., Furini, A., Russo, V., Pellegrinelli, A., Russo, P., 2014. Accuracy of Cultural Heritage 3D models by RPAS and terrestrial photogrammetry Int. Arch. Photogramm. Remote Sens. Spat. Inf. Sci, XL-5, 113-119. doi:10.5194/isprsarchivesXL-5-113-2014.

Brumana, R., Della Torre, S., Oreni, D., Cantini, L., Previtali, M., Barazzetti, L., Banfi, F., 2018. SCAN to HBIM-Post Earthquake Preservation: Informative Model as Sentinel at the Crossroads of Present, Past, and Future, in: Lecture Notes in Computer Science. doi:10.1007/978-3-030-01762-0_4.

Cantieni, R., Cantieni, C., Baudy-, I., Dübendorf, C., 2013. Langzeitüberwachung eines historischen Glockenturms Longterm Monitoring of a Historic Bell Tower.

Castellazzi, G., D’Altri, A.M., Bitelli, G., Selvaggi, I., Lambertini, A., 2015. From laser scanning to finite element analysis of complex buildings by using a semi-automatic procedure. Sensors, 15, 18360-18380. doi: $10.3390 / \mathrm{s} 150818360$.

Edelsbrunner, H., Mücke, E.P., 1994. Three-dimensional alpha shapes. ACM Trans. Graph., 13,1. doi:10.1145/174462.156635.

Guarnieri, A., Fissore, F., Masiero, A., Vettore, A., 2017. From Tls Survey To 3D Solid Modeling for Documentation of Built Heritage: the Case Study of Porta Savonarola in Padua. ISPRS Int. Arch. Photogramm. Remote Sens. Spat. Inf. Sci. XLII2/W5, 303-308. doi:10.5194/isprs-archives-XLII-2-W5-3032017.

Mill, T., Alt, A., Liias, R., 2013. Combined 3D building surveying techniques - Terrestrial Laser Scanning (TLS) and total station surveying for BIM data management purposes. J. Civ. Eng. Manag, 19, S23-S32.

Sánchez-Aparicio, L.J., Riveiro, B., González-Aguilera, D., Ramos, L.F., 2014. The combination of geomatic approaches and operational modal analysis to improve calibration of finite element models: A case of study in Saint Torcato Church (Guimarães, Portugal). Constr. Build. Mater., 70, 118-129. doi: 10.1016/j.conbuildmat.2014.07.106.

Selvaggi, I., Dellapasqua, M.., Franci, F.., Spangher, A.., Visintini, D.., Bitelli, G., 2018. 3D comparison towards a comprehensive analysis of a building in cultural heritage. ISPRS - Int. Arch. Photogramm. Remote Sens. Spat. Inf. Sci. XLII-2, 1061-1066. doi:10.5194/isprs-archives-XLII-2-10612018.

Selvaggi, I., 2017. Surveying and three-dimensional modeling for preservation and structural analysis of cultural heritage. University of Bologna, Italy - PhD Thesis.

Serantoni, E., Selvaggi, I., Wieser, A., 2017. Areal deformation analysis of a visco-plastic structure using point cloud data. Lienhart, W. Ingenieurvermessung 17, Beiträge zum 18. Int. Ingenieurvermessungskurs, 403-413.

Tang, P., Akinci, B., 2012. Formalization of workflows for extracting bridge surveying goals from laser-scanned data, in: Automation in Construction, 22, 306-319.

Vosselman, G., Maas, H.G., 2010. Airborne and Terrestrial Laser Scanning. Whittles Publishing. 